Roger Williams University

DOCS@RWU

\title{
Routine Crime in Exceptional Times: The Impact of the 2002 Winter Olympics on Citizen Demand for Police Services
}

\author{
Scott H. Decker \\ Arizona State University \\ Sean P. Varano \\ Roger Williams University, svarano@rwu.edu \\ Jack R. Greene \\ Northeastern University
}

Follow this and additional works at: https://docs.rwu.edu/sjs_fp

Part of the Criminology and Criminal Justice Commons

\begin{abstract}
Recommended Citation
Decker, Scott H., Sean P. Varano, and Jack R. Greene. 2007. "Routine Crime in Exceptional Times: The Impact of the 2002 Winter Olympics on Citizen Demand for Police Services and System Response." Journal of Criminal Justice 35 (1): 89-101.
\end{abstract}

This Article is brought to you for free and open access by the Justice Studies at DOCS@RWU. It has been accepted for inclusion in Justice Studies Faculty Publications by an authorized administrator of DOCS@RWU. For more information, please contact mwu@rwu.edu. 


\title{
Routine crime in exceptional times: The impact of the 2002 Winter Olympics on citizen demand for police services
}

\author{
Scott H. Decker ${ }^{\mathrm{a}, *}$, Sean P. Varano ${ }^{\mathrm{b}}$, Jack R. Greene ${ }^{\mathrm{b}}$ \\ a Department of Criminal Justice and Criminology, Arizona State University, 4701 Thunderbird Road, Glendale, AZ 85306-4908, United States \\ ${ }^{\mathrm{b}}$ College of Criminal Justice, Northeastern University, College of Criminal Justice, 405 Churchill Hall, Boston, MA 02115, United States
}

\begin{abstract}
Despite their rich theoretical and practical importance, criminologists have paid scant attention to the patterns of crime and the responses to crime during exceptional events. Throughout the world large-scale political, social, economic, cultural, and sporting events have become commonplace. Natural disasters such as blackouts, hurricanes, tornadoes, and tsunamis present similar opportunities. Such events often tax the capacities of jurisdictions to provide safety and security in response to the exceptional event, as well as to meet the "routine" public safety needs. This article examines "routine" crime as measured by calls for police service, official crime reports, and police arrests in Salt Lake City before, during, and after the 2002 Olympic Games. The analyses suggest that while a rather benign demographic among attendees and the presence of large numbers of social control agents might have been expected to decrease calls for police service for minor crime, it actually increased in Salt Lake during this period. The implications of these findings are considered for theories of routine activities, as well as systems capacity.
\end{abstract}

(C) 2006 Elsevier Ltd. All rights reserved.

\section{Introduction}

Despite a wide array of theories explaining crime, there has been surprisingly little criminological attention devoted to understanding the impact of exceptional events on patterns of routine crime or demands for a criminal justice response, most particularly police responses during such times. Such exceptional events could include natural disasters, terrorist acts, large-scale political, governmental, or international meetings, or sports-related events. These events are often concentrated in geographic space and may facilitate the opportunity for crime. At the same time, "routine" public safety needs outside concentrated geographic

\footnotetext{
* Corresponding author. Tel.: +1 602543 8067; fax: +1 602543 6658.

E-mail address: Scott.Decker@asu.edu (S.H. Decker).
}

spaces persist. Focusing criminological research and theory on such events to determine their influence on criminal behavior contributes to the understanding of crime, most particularly in a world where such events are present and represent an increasing challenge to communities and their response systems (Decker et al., 2005). It might be argued that criminal behavior occurring at times of natural disaster (flood, hurricane, earthquake, and the like) or terrorism might be explained by general criminological theories emphasizing anomie or opportunity. On the other hand, planned events like the Olympics, political conventions, and other major social or governmental mass attractions provide a fertile opportunity to examine the impact of such events on routine criminal activity. This article focuses on the impact of such planned events on theories of crime and police response using the 2002 Olympic Games in Salt Lake City. 


\section{Safety and security at the Olympics}

While the safety and security of athletes, staff, and spectators has perhaps always been a concern of the Olympic Games, events that took place in Munich in 1972 forever changed safety and security at such events. The murder of Israeli athletes by terrorists shattered the then prevailing myth that such athletic events transcended politics. The 1996 bombing in Centennial Park during the Atlanta games reinforced the potential for exceptional crime to take place during such international events and called into question understanding of how such events occur and their implications for local social control.

Two factors make the provisions of safety and security at the Olympic Games extremely important for consideration. First, the Olympic Games have very strong socio-political roots. The role of nationalism in the competition, among spectators and officials makes providing safety and security a somewhat more complex issue than for many domestic sporting events. Rather than "two sides" playing a game, there are dozens, even hundreds of "sides" or cultural interests that shape safety and security issues associated with Olympic events. The strong economic implications of the games, with billions of dollars committed and substantial opportunities for profit - or loss - also complicate the public safety response. The economic implications of the games are not limited to the events themselves, but also include the local economy and the infrastructure of the host city(ies) that may be affected during the course of the games.

Second, any Olympic security effort must manage both ordinary and extra-ordinary crime and public safety matters in the same geographic and social context, and at the same time. While Olympic security planners and line level personnel prepare for the worst, the reality is that they deal almost exclusively with mundane issues (Decker et al., 2005). These include responding to routine calls for service, crime and other public safety issues in the host city that occur outside, in, and around Olympic venues. The system must plan for, deploy resources to, and deal with both routine and exceptional crime, in and out of the Olympic envelope.

In addition to responses to crime (routine and exceptional), the management of interactions among the myriad players involved in Olympic safety and security is a complicated process and a key to successful operations. This is especially the case when the games are distributed throughout a city and its surrounding environs. Even given the varying conditions (range of venues and visitor populations) created in support of the Olympics, routine public safety must be maintained among the non-Olympic segments of the population as well. After all, these are the groups that will remain after the Olympics are long gone; they provide the basic tax revenues that support public safety and criminal justice before, during, and after the games.

The challenge of police responses to large-scale special events - in the present case the 2002 Salt Lake Winter Olympic Games is the key topic examined here. Specifically routine and non-routine crime during the Salt Lake Olympic Games are examined as well as the way such crimes test the capacity of law enforcement to respond to citizen demand for services. Key assumptions of routine activities theory as they are affected by the Olympic Games are examined. The presence of the games should affect many components of routine activities theory: (1) the presence of the games should attract motivated offenders, (2) routines within the hosting area are likely to be disrupted giving a large influx of "outsiders" to the games, but those people are likely focused on patterns of behavior which are particular to those who would victimize them (attendance at drinking establishments, scalping of tickets, unfamiliarity of the local area so as to remove some level of "rational decision making" on the part of the potential victims), and (3) both the number of suitable guardians as well as potential targets should be increased owing to increased police presence to accommodate large crowds of spectators. Taken together these changes to local "routine behavior" may also witness increases in crime and victimization. This analysis pursues this question.

\section{Routine crime in exceptional times}

As previously suggested, criminology has paid little attention to the impact of exceptional events, such as the Olympics, on patterns of routine crime and community demand for criminal justice services (Alpert \& Flynn, 2000). Planned events like the Olympics, political conventions, and other major events provide a fertile opportunity to examine the impact of such events on routine criminal activity and the ability of public officials to manage and respond to routine and exceptional crime. These types of exceptional events, whether planned or unplanned, hold the capacity for affecting crime patterns through a variety of mechanisms.

Routine activities theory is one suitable theoretical framework for understanding this relationship. Proponents of routine activities theory see crime as being largely shaped by the presence of suitable targets and motivated offenders who come together in time and 
space, mediated by guardians capable of preventing such events (Cohen \& Felson, 1979). The primary interest of the current research was to determine if largescale exceptional events fundamentally alter these dynamics in a way that changes crime patterns.

The Olympic Games and other similar large-scale events have the potential for upsetting the balance between suitable targets, motivated offenders, and the presence of capable guardians. Large events can result in shifting populations and possible changes to the physical environment. Shifting populations may be indicative of an influx of a large number of "strangers" into the host location, but also the possible mass exodus of "locals." Modifications to the physical environment often include changes to vehicle or pedestrian traffic patterns or target hardening measures such as security cameras. Finally, such events may also result in changes in the absolute number of "capable guardians" (e.g., police, non-police security personnel, or other personnel) or non-routine shifts in personnel among locations or assignments. All of these direct influences have the capacity to alter the dynamics of routine activities that are critical to the occurrence or prevention of directcontact predatory violations (Cohen \& Felson, 1979). The relative lack of empirical and theoretical attention to routine crime during such exceptional events is somewhat puzzling given the widely used theoretical foundation of routine activities theory.

\section{Literature review}

There is no widely accepted theoretical framework traditionally applied to the study of large-scale planned or unplanned events as researchers have generally failed to consider their impact on crime patterns. The few researchers who have considered this area of study have either applied the social disorganization or social cohesion traditions (Siegel, Bourque, \& Shoaf, 1999) to understanding the dynamics of such events. While such frameworks are useful, they fail to consider the more likely impact of such events on patterns and characteristics of "normal" or "routine" social interactions.

\section{Previous research}

Unplanned events such as earthquakes, fires, blackouts, and other natural disasters offer a parallel to the effect of exceptional events such as the Olympics on routine crime. While such events are unplanned, they reflect many of the challenges faced by planned events. For each category of event (planned or unplanned), there is an area of primary activity where resources are heavily concentrated, as well as "routine" areas where things proceed "as usual." Each type of event also places strains on available technical or personnel resources. Most research in this area had found little effect of the exceptional event on routine patterns of crime.

Siegel et al. (1999) examined patterns of crime, victimization, and traumatic stress following the Northridge earthquakes in 1995. They found static patterns across each of their measures, and suggested that events such as an earthquake did not have much impact on routine crime and stressors or at least that stressors produced by natural disasters and community cohesion might balance each other out in terms of their impacts. The authors did not specifically test the tenets of a given theory, but instead hypothesized that post-event increases in both measures would fit the ideas of social disorganization and decreases in both would be suggestive of community social cohesion. Instead, they found few changes in either measure. Similarly, few changes were found in predicted property crime rates and actual rates after the Quebec ice storm of 1998 (Lemieux, 1998). The authors did note, however, that an increased police presence, the increased military presence, and the distribution of relief checks were related to small decreases in property crime. Preliminary assessment of the impact of such events, then, suggests large-scale natural disasters have little-to-no discernible impact on crime patterns, especially violent crime.

Perhaps the best examples of the impact of exceptional events on routine crime can be found in the great Northeast blackouts, in New York City in 1965 and 1977. Remarkably, the primary source of such information is anecdotal. The Blackout History Project (1965) reported few criminal incidents, consistent with the increase in social cohesion hypothesized by Siegel et al. (1999), when New Yorkers assisted each other and behaved in ways that suggested an increase in informal regulation and community social cohesion.

The results from the 1977 blackout, however, were somewhat different (Blackout History Project, 1977). Several areas of the city experienced arson, looting, and increased levels of violence. The police reported making in excess of 4,000 arrests and the city experienced $\$ 60$ million in damage. The 1977 blackout occurred during a time of economic cutbacks in social services, and it is argued that those cutbacks created an atmosphere in which the informal regulatory power of the community had already been eroded, leaving the community vulnerable to the effects of the blackout.

One examination of the blackout's effects revealed that crime characteristics reflected patterns of social 
disorganization. Genevie et al. (1987) compared ten areas where looting of stores took place to ten where looting was not found. Information was collected from roughly thirty individual respondents in each neighborhood through random sampling methods and in-person interviews. There was strong correspondence between the reported levels of looting by survey respondents and those officially counted; the researchers concluded that their results had high external validity. Looting was strongly correlated with high levels of neighborhood social problems, such as unemployment, fear of crime, and social disorganization. In addition, where residents felt more positive about the police, looting was lower. These results provided support for the conclusions that higher levels of social problems were related to levels of disorder and crime after an exceptional event such as the blackout. Of course these findings are based on anecdotal evidence and must be interpreted with caution.

New York City experienced another large-scale blackout in 2003 (CNN, 2003). Emergency services (police, fire, and EMS) responded to more than 80,000 calls for service, more than double than what was typical. Police reported, however, that the roughly 850 arrests made that evening were fewer than would be expected on a comparable summer night. The relatively static level of crime overall during the 2003 blackout apparently did mask an increase in burglary, roughly double the number recorded on the same day the previous year ("Wasn't So Calm," 2003).

Detroit was also affected by the blackout of 2003. Despite its history of urban riots and social disorganization, there were few incidents reported during the blackout in Detroit and the level of arrests seemed consistent with patterns in other blackout cities (Hansen, 2003). Collectively, these results offer little conclusive evidence about the effects of three large-scale blackouts experienced in the past thirty years. Perhaps the most solid conclusion to draw from this event is the importance of the social and economic context at the time the blackout occurs.

The evidence about the impact of unplanned events on crime patterns is not well understood, offering little opportunity for generalization. In this context, it is important to juxtapose large-scale unplanned events such as natural disasters or terrorist attacks to planned events such as the Olympic Games, papal visits, and other political events. Juxtaposing such events can help to understand the impact of planning and preparedness. The Salt Lake City Olympic Games, as an example of special events policing, provide an opportunity to apply principles of rational choice to special events and assess the extent to which these principles compare to more general standards of social control.

Routine activities theory offers several plausible hypotheses as to how large-scale exceptional events may influence crime rates. First, most of the spectators are outsiders, not a part of the normal regulatory processes at work in the area and unfamiliar with the local mechanisms of formal social control. As such, they serve to reduce the level of guardianship and increase the vulnerability to victimization in a community during an event such as the Olympics. Second, opportunities for crime are increased during the Olympics in part because of the presence of a large number of strangers in renting houses and utilizing local services. In addition, visitors increase crime opportunities because they typically engage in lower levels of guardianship than permanent residents. In a sense, being on vacation is often accompanied by a reduced level of attention to daily cares, including those associated with guardianship.

Finally, motivated offenders may be drawn to the games to take advantage of what are perceived to be "easy marks," individuals paying attention to entertainment rather than matters of personal safety. The Olympic Games are accompanied by a number of social and cultural events that attract large numbers of people for the purpose of celebration. The "theme" tents sponsored by alcohol producers and the open-air street markets that accompany such events are two good examples of this. Indeed, the single most dramatic security event in Salt Lake occurred on eve of the closing ceremony in just such a venue.

\section{Crime and the Olympics}

The Olympic Games is one of the largest of all worldclass sporting events held in one location. The games capture a number of dynamics that can be found in special events in the United States including the World Series, Super Bowl, visits from foreign religious and political dignitaries, political conventions, and large music festivals. On the world stage, economic and political summits, World Cup Soccer, and similar events like the Olympics tax the capacity of hosting jurisdictions to respond to issues of safety and security.

Little research had been conducted on the impact of the Olympic Games on routine crime. The small body of work that existed on this topic suggested that the Olympics had little impact on local crime. For example, the Olympic Intelligence Centre reported that crime rates during the games in Sydney, Australia were consistent with figures reported from the prior year 
(Schwendiman, 2001). This report focussed on crimes committed and recorded within the Olympic envelope, the areas specifically designated as hosting venuerelated events, as compared to the greater Sydney area. For example, the Sydney Olympic Intelligence Centre (Schwendiman, 2001) reported 340 offenses committed during the games in the main Olympic venue, an average of eleven crimes per day, with theft being the modal (79 percent) category.

There are several countervailing forces that confound the understanding of crime rates in the context of the Olympic Games. First, there is a dramatic presence of law enforcement within the Olympic envelope, increasing the number of sworn officers. Though these officers are concentrated in a small geographic area, their sheer numbers may deter crime around competition venues, official Olympic sites (housing, official officers, etc.) and outside the Olympic envelope. This increase in law enforcement personnel directly increases the number of capable guardians available to prevent and respond to crime. That said, expectations about "routine" crime in neighborhoods outside the Olympic envelope might be quite different. During the Salt Lake games (as was the case for Atlanta in 1996 and Sydney in 2000), 40 percent of sworn officers were assigned to the Olympic envelope, leaving the neighborhoods to be patrolled by a substantially reduced force. Thus, there may be an increase in the number of capable guardians in the host jurisdiction(s) as a whole that may mask decreases within non-venue areas within the same jurisdiction(s) - while there may be more police, they are deployed largely in service to the games and less so to the surrounding communities.

Second, the influx of large numbers of spectators, officials, and participants actually swells the denominator in the rate of reported crime. It was estimated that the summer games in Sydney attracted nearly 6,500,000 spectators (Schwendiman, 2001) to the games and that more than 2,000,000 visitors attended the games in Salt Lake. These spectators - by and large-are affluent, law-abiding citizens, though potentially attractive targets for victimization. The "suitability" of the influx of visitors may be enhanced by their likely ignorance of known problem areas and possible lack of knowledge about local subcultural norms. The impact of temporary populations may lead to an incorrect assumption about crime patterns as their numbers are not captured in the residential population figures, the denominator in crime rates.

Large planned or unplanned events hold the capacity for affecting the critical dimensions of routine activities theory: suitable victims, motivated offenders, and capable guardians. Routine activities theory shifts the focus of inquiry away from offenders and to the criminal event itself (Cohen \& Felson, 1979). It does so in a way that reflects the complex interactions between victims, offenders, and locations that produce "crime." In this context, suitable victims and motivated offenders come together in time and space to create the opportunity for crime. The likelihood of crime occurring is increased when guardians capable of preventing or deterring such events are absent. Crime then is a byproduct of the "routine activities" of individuals that structure their interactions with others, the locations they frequent, and social circumstances they encounter. Brantingham and Brantingham (1993, pp. 261-263) consider several assumptions of the routine activities perspective that are directly relevant to this discussion:

"The decision process leading to the commission of any particular crime begins with someone who is in a state of readiness for crime; neither motivated offenders nor opportunities for crime are uniformly distributed in space and time; and target suitability is tied both to the characteristics of the target and to the characteristics of the target's surroundings."

Routine activities theory presupposes that there are features of places that make them more or less conducive to crime. That crime is not distributed in random spatial patterns is an accepted principle of criminological theory. The notion of crime "hot spots" is suggestive of the understood fact that crime tends to be heavily concentrated in reasonably discrete areas. Brantingham and Brantingham (1995) argue that places can be crime "generators" or crime "attractors." Bars and similar establishments can be generators of crime in that they produce or create the social circumstances that result in problems. In other circumstances, places might be considered to be "attractors" of crime, that is, there are features of land use or social interaction that attract crime-prone individuals. Arcades, bus stops, or city parks could fulfill the role of "attractor" in that they attract individuals of varying criminal propensities to meet in time and space, thereby creating opportunities for victimization.

\section{The context of the games in Salt Lake City}

The social, political, and economic context of the host jurisdiction ultimately shape safety and security for all Olympic Games. This includes how security is designed and implemented, the nature of the local geographic context (tightly concentrated or dispersed), and of course, the crime experiences of the local 
jurisdictions before the Olympics comes to town. Each of these factors shapes the patterns of crime and responses from the community and government. A significant part of the crime context for the Salt Lake Games was that the games occurred approximately four months after the events of September 11, 2001, creating a larger federal presence for this Olympics than any other games held in the U.S.

The security planning for the Utah games spanned seven years and included more than $\$ 310$ million spent on security for the games. In total, nearly 12,000 individuals worked in a security role during the games $(11,848)$. Of this total, 6,553 were sworn police officers, including 2,225 Utah state and local sworn officers and 2,100 federal sworn officers. ${ }^{1}$

The military contributed 3,500 individuals to the security effort, with 695 law enforcement volunteers, and 1,100 fire and emergency management services personnel (Governor's Office, State of Utah, 2002, p. 26). The authorized strength of the Salt Lake City Police Department was 415 sworn officers, but at the time of the Olympics the department functioned with roughly 400 officers. The state of Utah had only twenty law enforcement departments with fifty or more sworn officers, with Salt Lake City and Salt Lake County being the two largest police agencies in Utah. In sum, the influx of new security personnel for the Olympic Games exceeded the sworn capacity of all police departments in the state of Utah.

In the end, 40 percent of the Salt Lake City Police Department's officers were assigned to Olympic duties. Such assignments typically began two weeks before the opening of the games, and concluded shortly after the closing ceremonies of the Para-Olympic Games that immediately follow the Olympics. This deployment strategy resulted in 60 percent ( 240 officers) of the Salt Lake City Police Department workforce being dedicated to "routine crime" outside the Olympic envelope. Such workload shifts had implications for public perceptions of police response, as well as for the capacity of the police to respond to public demands for service. As such, this represents a potentially interesting and important test of the relationship between resources, the community demand for services, and police response.

Salt Lake City, Utah is located in the Wasatch Valley in North Central Utah, and the city of Salt Lake City has a population of 184,723 residents. West Valley $(110,000)$, Ogden $(78,492)$, and Clearfield $(26,400)$ are the next largest cities in the metropolitan statistical area. The mountainous nature of the terrain surrounding Davis, Salt Lake, Summit, Wasatch, and Weber counties makes the region geographically isolated from other population centers, making it an excellent site for a Winter Olympics and a more challenging site from the perspective of security.

Crime in Salt Lake City provided another part of the context of public safety for the Olympic Games. In 2001 (the year before the 2002 Winter Games), Salt Lake City recorded eighteen homicides, a rate of 9.7 per 100,000 residents. That rate was slightly higher than the rate for the U.S. as a whole, and put the city's homicide rate near the bottom for homicides in cities its size. For the city of Salt Lake, a violent crime rate of 631 per 100,000 was recorded for 2001. The U.S. rate per 100,000 citizens for 2001 was 504, somewhat lower than that for Salt Lake. The property crime rate for Salt Lake City was 8,267 per 100,000 residents compared to a U.S. rate of 3,656 per 100,000 . In general then, while Salt Lake had a lower homicide rate compared to that of large U.S. cities for 2001, other violent and property crime rates in Salt Lake were higher than the U.S. average. At minimum, this suggests that Salt Lake City was generally kept busy in responding to "routine" crime.

\section{Study design}

This study examined three issues: changes in the pattern of routine crime, the impact of the Olympic Games on citizen demand for police services and the response of law enforcement to crime during the games. All three measures were included because of the potential impact that the reduced police force would have on these measures. This design employed official data, including computer-aided dispatch data, crime reports, and arrests provided by the Salt Lake City Police Department. These data were used to test the key assumptions outlined above, namely, that the presence of the games in a community alters one or more dimensions of routine activities theory, which results in a discernible change in crime patterns.

\section{Measures}

Three specific sets of data are used to address these hypotheses. The first of these data sources was calls for service. Calls for service were measured from the Computer Aided Dispatch (CAD) system of the Salt Lake City Police Department. CAD data represent a measure of citizen demand for services. During periods of reduced guardianship caused by an exodus of local residents (such was the case with the Salt Lake City games), it would be expected that citizens' calls to the police, especially for less serious offenses such as 
quality of life crimes, might decline. Calls for service data are important because they are independent measures of citizen demands for service and do not reflect police-initiated activity.

The second measure examined was crime data reported by the Salt Lake City Police Department (e.g., crime incidents). This measure was an indication of the extent to which calls for service or on-view events were deemed to rise to a sufficient level of legal sufficiency to result in a police report. This figure also represents a measure of police activity, as a measurable fraction (perhaps 10 or 20 percent) of crime reports are generated by officer-initiated actions instead of requests for service by the community. Crime reports represent a decision by line level officers and their managers to invest the limited available resources (especially during the games) in specific offenses.

The third measure in the data was arrests. Arrests are an indicator of police activity and responsiveness to citizen demands for service. Like crime reports, arrests represent a decision by law enforcement to invest resources in the response to crime. Taken in tandem, these data represent a wide range of demands and strains placed on law enforcement personnel before, during, and after the Olympic Games.

These three measures were obtained from the Salt Lake City CAD and Records Management System (RMS) for the period of eighteen months prior to the Olympic Games and seven months following their conclusion. This allowed for a sufficient number of weeks prior (seventy-three weeks), during (three weeks), and after the games (twenty-six weeks) that can both de-trend the analyses as well as examine the effects of seasonality.

\section{Analyses}

The primary goal of this research was to understand the impact of the Salt Lake Olympics on local routine crime as measured by calls for service, official police incidents, and arrests. The routine activities perspective presents several plausible hypotheses about how large exceptional events might influence official crime measures. It could be reasoned that the presence of Olympic Games would effectively result in a spike in calls for service, official incidents, arrests. In terms of calls for service, the games could be expected to result in an increase in the number of reported crimes commensurate with the increase in suitable targets. Similarly, both recorded incidents and arrests could be expected to go up to reflect possible actual increases in victimization but also increases in police personnel (capable guardians) that are able to detect and respond to apparent violations of the law.

It is also possible that large planned events would result in decreases in all three measures. In this scenario, the volume of calls for service might be expected to decrease for two distinct but related reasons. For crime outside the Olympic envelope, victimization might drop as a result of substantive alterations to routine activities caused by an exodus of individuals from the general area and alterations to daily routines by those remaining. For crime inside the Olympic envelope, increased security personnel and target hardening strategies (e.g., visible security presence and security cameras) might function as deterrents. Decreases in official incidents and arrests could be experienced outside the Olympic envelope as the number of guardians capable of detecting and responding to "routine crime" is redirected inside venue areas. Decreases in arrests and incidents might also be realized inside the envelope due to increases in capable guardians. Such an analysis is well suited for time series methods.

The first step in the analysis plan explored the statistical difference in the means for the three data sources before, during, and after the games. A one-way analysis of variance model (ANOVA) was used to test for statistically significant differences in these means. In addition to a means comparison, a Tukey post-hoc analysis technique provided for multiple comparisons of groups to determine statistical differences between subgroups. To further test for a significant effect of the games on police workloads, time series analysis was used to test whether pre-post Olympics trends were significantly different from workload levels that occurred during the Olympics.

\section{Findings}

\section{Comparison of means}

The average number of weekly calls for service, police incidents, and arrests are detailed in Table 1 (trend charts are included in Appendix A for reference purposes).

The Salt Lake City Police Department received an average of 4,553 calls for service per week in the seventy-three weeks prior to the start of the Olympics (February 8, 2000). The average number of weekly calls for service increased only slightly to 4,635 during the games. This represented a negligible increase of 2 percent or approximately eighty calls per week. There also continued to be a slight increase in calls for service after the games that represented a 3 percent increase over the pre-games weekly average. ${ }^{2}$ 
Table 1

Comparison of weekly average of calls for service, police incidents, and police arrests by time period

\begin{tabular}{llllcrr}
\hline & $\begin{array}{l}\text { Pre } \\
(73 \text { weeks })\end{array}$ & $\begin{array}{l}\text { During } \\
(3 \text { weeks })\end{array}$ & $\begin{array}{l}\text { Post } \\
(27 \text { weeks })\end{array}$ & $\begin{array}{l}\text { Pre-during games } \\
\text { change }\end{array}$ & $\begin{array}{l}\text { During-post } \\
\text { games change }\end{array}$ & $\begin{array}{l}\text { Pre-post games } \\
\text { change }\end{array}$ \\
\hline Calls for service & 4,553 & 4,635 & 4,679 & $2 \%$ & $1 \%$ & $3 \%$ \\
Incidents** & 1,344 & 1,141 & 1,341 & $-15 \%$ & $18 \%$ & $0 \%$ \\
Arrests *** & 407 & 216 & 381 & $-47 \%$ & $76 \%$ & $-6 \%$ \\
\hline
\end{tabular}

$* * \mathrm{p}<.01$

$* * * \mathrm{p}<.001$.

In all, the average number of calls for service remained reasonably static at approximately 4,600 calls per week over the entire analytic period. This suggested that there was no statistically significant increase in demand for public safety services by the community as a whole during the Olympics, but equally important no decline in such calls either.

The comparison of means for police generated incidents and arrests tells a different story. The SLPD averaged approximately 1,344 recorded police incidents per week in the seventy-three weeks before the commencement of the Olympics. The total number of recorded police incidents decreased by 15 percent or 203 incidents per week below the pre-game weekly average during the games. The post-hoc analysis indicated there was a statistically significant decrease of 203 weekly incidents during the games and a subsequent statistically significant increase of 200 weekly incidents afterwards. This analysis indicated the pre $(1,344)$ and post $(1,341)$ weekly averages were statistically indistinguishable, and that whatever measurable effect occurred during the Olympics went away at their conclusion.

The arrest data showed a pattern similar to that of the police incident data. SLPD recorded approximately 400 arrests per week in the seventy-three weeks leading up to the games. The weekly mean dropped almost 50 percent to an average of 216 arrests per week during the games. Also similar to the incident data, the weekly average number of arrests also quickly increased to 381 arrests in the thirty-one weeks following the games. The ANOVA analysis indicated a statistically significant difference in means (d.f. $=2 ; \mathrm{F}=23.11 ; \mathrm{p}<.000$ ). The Tukey's post hoc analysis indicates there was a statistically significant decrease of 191 weekly arrests during the games and a corresponding statistically significant increase of 165 weekly arrests after the games. Although the post-games weekly average remained 6 percent less than the pregames average, the difference was not statistically significant.

In summary, the comparison of means tests indicated that the Olympic Games had differential effects on the various measures of demands for police services. The measures could be largely distinguished by the source of the workload or demand. The ANOVA model suggested the Olympics did not have a statistically significant effect on citizen demand for services as measured by calls for service data, but did in fact have a statistically significant effect (decrease) on indicators of law enforcement controlled workload measures. This would indicate a decline in the ability of the police to respond to calls for service, largely in part because of the deployment of a substantial part of the force to the Olympic mission.

\section{Interrupted time series analysis}

ARIMA models were used to further test the impact of the Olympic Games on routine police workload (Box \& Jenkins, 1976; Box \& Tiao, 1975). There are several features of time-specific sequentially ordered data that make the ARIMA technique particularly useful. ARIMA techniques are effective in parsing out the effects of seasonality and time dependency among observations (e.g., data points) that are common features of time sequenced data. After controlling for these features of time ordered data, the ARIMA model also provides an analysis of the effects of discrete interventions. This "interrupted" time series compares pre and post intervention trends while controlling for seasonality and data dependency. The application to the current problem and data seemed particularly appropriate.

ARIMA analysis involves an iterative model building process where the analyst diagnoses the structure of the trend and then builds the appropriate statistical model to test the effects of an intervention. ARIMA models have three structural parameters that must be diagnosed and modeled, autoregressive (p); difference (d); and moving average (q) parameters (see McDowall, McCleary, Meidinger, \& Hay, 1980). For the parameters of a time series model to be estimated correctly, the series or trend must be stationary. Stationarity refers to the degree to which the data series fluctuates or varies around a fixed mean. A nonstationary trend is 
represented by a nonzero integer in the $d$ term. The differencing process involves subtracting a value from the preceding $k^{\text {th }}$ observations with $k$ representing the $d$ parameter. The autoregressive parameter reflects the mathematical relationship between an observation and $k$ preceding values. The most common autoregressive function is the first-order process represented by ARIMA (1, d, q) (McDowall et al., 1980, p. 32). Finally, the moving average parameter $(q)$ is similar to the autoregressive parameter except that it represents the affects of past error that cannot be modeled with the autoregressive parameter. ${ }^{3}$

\section{Model identification process}

Since each of the data series included a discrete intervention period (the start and end of the Olympics), the trends were diagnosed using the seventy-three pregames observation points. The initial autocorrelation (ACF) and partial autocorrelation (PCF) autocorrelograms indicated a substantial spike at lag 1 that was sustained for several lag periods. ${ }^{4}$

Similar procedures were used to diagnose and model the trend for the official police incident and arrest data. Police incident and arrest data were used because, when coupled with the calls for service data, they presented an extensive picture of the demand for police services and the degree to which police translated "demands" into countable crimes and arrests. ${ }^{5}$ Similar to those for the call for service data, the ACF distribution showed a significant spike at lag 1 that was sustained for several additional lags. The initial spike that was sustained for several subsequent lag periods suggested a second order autoregressive process. To test the adequacy of the tentative ARIMA $(2,0,0)$ model, the generated error term was modeled to discern if the distributions for any lag periods reached statistical significance. The figures indicate the error term was reduced to white noise and that the police incident data fit the ARIMA $(2,0,0)$ model. The same findings were evident when the ARIMA $(2,0,0)$ model was diagnosed using the full time series (figures not shown). Collectively these findings provided strong evidence for a change in the pattern of data during the Olympics from the pre-and post-game periods.

The initial autocorrelograms for the pre-intervention arrest trends also revealed a significant spike at lag 1 that decayed abruptly for the following two lags only to reveal another series of spikes for lags 4, 5, and 6 . This was indicative of an autoregressive trend, but it was unclear if the trend was a first or second order trend. Two models were constructed and diagnosed where the autoregressive term was assumed to be a first and then second order term. The model was rerun assuming the autoregressive term to be both first and then second order. The modeled error term for the ARIMA $(1,0,0)$ series (available from the authors) graph indicated no significant spikes in the lag series suggesting the data fit the time series and the remaining error was reduced to random error. The same process was followed to test if the time series fit the ARIMA $(2,0,0)$ model and again the findings were largely the same. The modeled error term did not exhibit any significant lags. When modeling time trends, one goal should be to establish a parsimonious model thereby reducing it to its simplest state. Since the two models seemed to behave similarly, the ARIMA $(1,0,0)$ model seemed to be the best fit.

\section{Effects of Olympic on police workloads}

Once the trend series were diagnosed, the final step in the analysis was to model the data series and determine if the CAD, incident, and arrest trends during the games were significantly different from the pre-post games trends. Intervention components can be abrupt or gradual and can be either temporary or permanent in duration (McDowall et al., 1980). In this case the games were considered an abrupt, temporary intervention since there was a definable intervention period with a start and stop of approximately three weeks. A dummy variable was used to denote the time periods representing the presence of the games with (1) indicative of the games and (0) their absence. For purposes of this analysis weeks six, seven, and eight of 2002 were considered the intervention time periods. Controls for seasonality were introduced by including three dummy variables representing winter (December, January, and February), spring (March, April, and May), and summer (June, July, and August) with fall (September, October and November) held as the reference category. Compared to fall, the findings indicated a significant increase in calls for service during the summer months. The Salt Lake City Police Department reported approximately 361 additional weekly calls for service between June and August. After controlling for seasonality, the affects of the Olympics on calls for service could be isolated more clearly. The findings also indicated a significant increase of approximately 474 weekly calls for service during the Olympic Games. The effect of the Olympics was first tested on calls for service data. The ARIMA $(2,0,0)$ model was analyzed including the Olympics dummy variable. The results of the time series analysis are presented in Table 2. 
Table 2

Weekly numbers of calls for service for entire series- ARIMA $(2,0,0)$ model

\begin{tabular}{lrrrr}
\hline Parameter & Coefficient & $\begin{array}{l}\text { Standard } \\
\text { Error }\end{array}$ & T-ratio & Probability \\
\hline AR1 & 0.737 & 0.113 & 6.496 & 0.000 \\
AR2 & -0.061 & 0.117 & -0.525 & 0.601 \\
Olympics* & 474.058 & 222.109 & 2.134 & 0.035 \\
& & & & \\
Seasonality (fall reference) & & & \\
Winter & -171.031 & 152.118 & -1.124 & 0.263 \\
Spring & -181.855 & 155.860 & -1.167 & 0.246 \\
Summer* & 360.533 & 151.808 & 2.375 & 0.020 \\
\hline
\end{tabular}

The same strategy was used to contrast the weekly trends in official police incidents during the Olympics from the other observation points both before and after the games. Table 3 provides the parameter estimates for the model that also includes controls for seasonality. In terms of seasonality, the findings report somewhat higher levels of weekly arrests during winter, spring, and summer compared to the reference category although none, except for summer, near statistical significance. The data also suggest SLPD experienced a reduction in recorded police incidents during the Olympics that approximated 113 per week.

The time series model presented in Table 4 gives the parameter estimates for the model that includes weekly aggregated arrests. Interestingly, there was no apparent seasonal effect in the data. This stood in contrast to the previous two trends that demonstrated a significant or one that neared statistical significance in the case of the incident data. The presence of the Olympic was correlated with a significant reduction in weekly police arrests of approximately 128 per week. This reduction is particularly important when one considers this represents a reduction of over 31 percent (based on the preintervention weekly trend of 407) of the base rate.

The initial comparison of means tests suggested that while the presence of the Olympic Games did not have a

Table 3

Weekly numbers of weekly official police incidents- ARIMA $(2,0,0)$ model

\begin{tabular}{lrrrr}
\hline Parameter & Coefficient & $\begin{array}{l}\text { Standard } \\
\text { Error }\end{array}$ & T-ratio & Probability \\
\hline AR1 & 4.447 & 0.100 & 4.451 & 0.000 \\
AR2 & 0.228 & 0.102 & 2.233 & 0.028 \\
Olympics & -113.060 & 59.822 & -1.889 & 0.062 \\
& & & & \\
Seasonality (fall reference) & & & \\
Winter & 23.408 & 42.082 & 0.556 & 0.579 \\
Spring & 40.339 & 43.986 & 0.917 & 0.361 \\
Summer & 83.291 & 42.738 & 1.949 & 0.054 \\
\hline
\end{tabular}

Table 4

Weekly numbers of weekly police arrests- ARIMA $(1,0,0)$ model

\begin{tabular}{lrrrr}
\hline Parameter & Coefficient & $\begin{array}{l}\text { Standard } \\
\text { Error }\end{array}$ & T-ratio & Probability \\
\hline AR1 & 0.472 & 0.092 & 5.155 & 0.000 \\
Olympics & -127.967 & 33.290 & -3.844 & 0.000 \\
& & & & \\
Seasonality & (fall reference) & & & \\
Winter & -9.167 & 19.296 & -0.475 & 0.636 \\
Spring & 31.702 & 19.250 & 1.647 & 0.103 \\
Summer & 22.308 & 18.808 & 1.186 & 0.238 \\
\hline
\end{tabular}

significant affect on the weekly level of calls for service received by the Salt Lake City Police Department during the games, it did result in a significant reduction in police incidents and arrests.

In an effort to further disentangle the effects of the Olympics on police workloads, the effects of the games on weekly workload trends using time series analysis were examined. This analytical strategy is effective in controlling for the effects of seasonality and other features of trend variation. In summary, the findings indicated the Olympics resulted in a significant increase in citizen demand for service but a corresponding reduction in police controlled outputs.

Finally, it may be that the findings may mask the effects of subcategories of offenses. That is, violent, property, and public order crimes may not behave in a similar fashion, and the patterns observed here could be attributed to changes in one of these offense types. In order to test this assumption, the mean values for each data source (incidents and calls for service) were compared for each of these three crime types. The results are presented in Table 5, and only one significant offense (total calls for service) was found. Thus these findings did not hinge on a single crime type, but rather reflected crime in general.

\section{Conclusions}

The impact of special events on patterns of routine crime raises questions about the extent to which such special events have an impact on routine crime, and whether they challenge the institutional capacity that provides safety and security during those events. Based on data from Salt Lake before, during, and after the 2002 Salt Lake City Winter Olympics, the results suggested that Salt Lake, in attempting to absorb nearly 2,000,000 visitors experienced an accompanying spike in community concern for routine crime. Crime concern, as measured by citizen calls for police service, was affected by the presence of the Olympics, 
Table 5

Mean comparisons of incidents and calls for service (CFS) by time group

\begin{tabular}{|c|c|c|c|c|c|c|c|c|c|}
\hline \multirow[t]{2}{*}{ Event types } & \multicolumn{2}{|c|}{ Before $(n=73)$} & \multicolumn{2}{|c|}{ During $(\mathrm{n}=3)$} & \multicolumn{2}{|c|}{ After $(n=27)$} & \multicolumn{3}{|c|}{ Total (103) } \\
\hline & Mean & Std. Dev. & Mean & Std. Dev. & Mean & Std. Dev. & Mean & $\mathrm{N}$ & Std. Dev. \\
\hline Total incidents* & $1,312.6$ & 122.7 & $1,125.3$ & 62.6 & $1,309.6$ & 58.9 & $1,306.4$ & 103 & 112.2 \\
\hline Total CFS & $4,554.9$ & 353.8 & $4,629.3$ & 195.5 & $4,678.8$ & 631.1 & $4,589.5$ & 103 & 440.0 \\
\hline Property crime incidents & 441.5 & 49.3 & 410.7 & 25.6 & 461.6 & 37.3 & 445.9 & 103 & 46.9 \\
\hline Property crime CFS & 407.6 & 38.5 & 424.3 & 41.4 & 418.9 & 42.2 & 411.1 & 103 & 39.5 \\
\hline Violent crime incidents & 106.2 & 16.9 & 97.0 & 14.8 & 111.1 & 16.8 & 107.2 & 103 & 16.9 \\
\hline Violent crime CFS & 227.4 & 30.4 & 221.3 & 21.0 & 231.7 & 27.8 & 228.3 & 103 & 29.4 \\
\hline Public order incidents & 250.3 & 29.2 & 281.3 & 22.5 & 259.1 & 26.1 & 253.5 & 103 & 28.7 \\
\hline Public order CFS & $1,027.5$ & 127.9 & $1,030.7$ & 82.3 & $1,083.0$ & 115.3 & $1,042.1$ & 103 & 125.2 \\
\hline
\end{tabular}

$* \mathrm{p}<.05$.

suggesting that the games affected community capacity for absorbing large numbers of "outsiders," while at the same time maintaining a sense of community that afforded such an accommodation. Community concern with crime measured by calls for service declined. Time-series analysis revealed that such concerns increased in the Salt Lake community during the Olympics.

The presence of a detectable community concern for crime can be attributable to many factors. In Salt Lake community tolerance of "routine crime" was not observed, as calls to the police appear increased outside the Olympic envelope. These increases in crime concern may be attributable to the massive influx of people into the Salt Lake community.

A related explanation emphasizes other social conditions that affect public concern for crime, as measured by calls for service. The location of the 2002 Winter Games (Salt Lake) and the demographic profile of visitors would be expected to contribute to a lessening of significant concern for police action (as measured by calls for service). Salt Lake is a physically isolated, relatively homogenous medium-sized community, surrounded by many smaller communities. Such physical isolation played a role in who actually came to the Winter Games. In a related way, the demographic characteristics of those attending the Salt Lake Games were an important factor in shaping crime and the citizen response to crime. The Salt Lake Games attracted many who were affluent enough to get to Utah and afford the accommodations. Unlike the hooliganism linked with the World Cup and other international soccer events, winter sports have typically been held at small, expensive places. Despite the attraction of "similar others" to those in the local Salt Lake community, the overwhelming number of visitors may have set off local concerns for safety and order, even in the absence of "symbolic assailants." The physical isolation may have actually attenuated concerns for "routine crime" as the flood of visitors to the Salt Lake Olympic Games likely overwhelmed residents and strained the capacity of public safety and law enforcement. In a community where local order is maintained at a relatively high level, such a dramatic increase in visitors may have strained the capacity of the local community and public safety officials.

Taken together, the local pride for hosting the Olympics, a perhaps less disorderly or crime-focused clientele, and a rather physically isolated location should have all worked together to reduce calls to the police. The analysis revealed that despite such factors, community concern for crime (measured by calls for police service) increased.

On the matter of police initiated activity (e.g., police incidents and arrests), the increased demands on the police appeared to have produced changes in the weekly averages of these activities before, during, and after the Olympics. Here the system capacities appeared to have affected police decisions about incidents and arrests. In both cases, the capacity of the Salt Lake Police Department was stretched across two fronts - providing public safety services in areas immediately surrounding the Olympic venues, as well as to the broader residential and business communities in Salt Lake. It appeared that the diversion of a substantial proportion of police resources (upwards of 40 percent) resulted in fewer incidents and arrests during the Olympics, but that such activity and outcomes returned to their "normal" rates once the games were completed. Incident and arrest outcomes appeared to be the result of system capacity; that is, the availability of the police to define and take action, especially in the face of increased demand as previously discussed.

There were several potential limitations to this study. First, this was a study of a single event, albeit the largest sporting event in the world. Testing the 
theoretical and empirical findings from this analysis against other experiences including natural disasters (floods, hurricanes, tornadoes, tsunamis), as well as exceptional events such as terrorist attacks or threats, was important to confirm or reject the findings here. In addition, it was not possible to fully control for the denominator in crime and demand for police services. There was a large influx of visitors, spectators, and participants during the Olympics, as well as an out-migration of large numbers of residents. Owing to measurement difficulties, this was not fully accounted for.

\section{Appendix A. Trend charts}

Fig. 1. Call for service trends

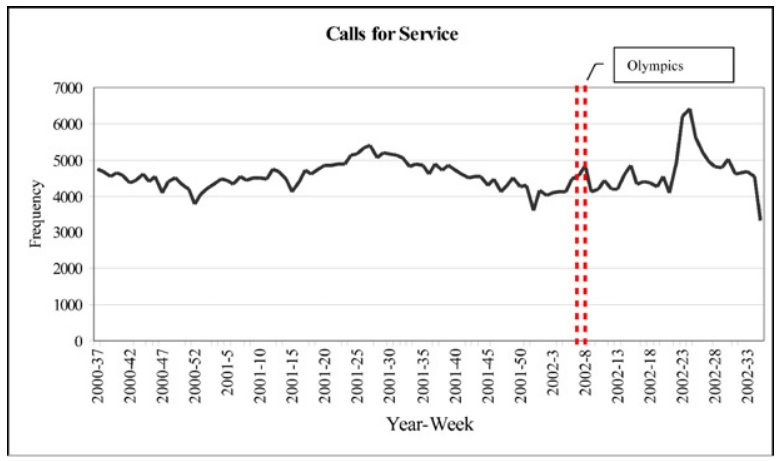

Fig. 2. Crime incident trends

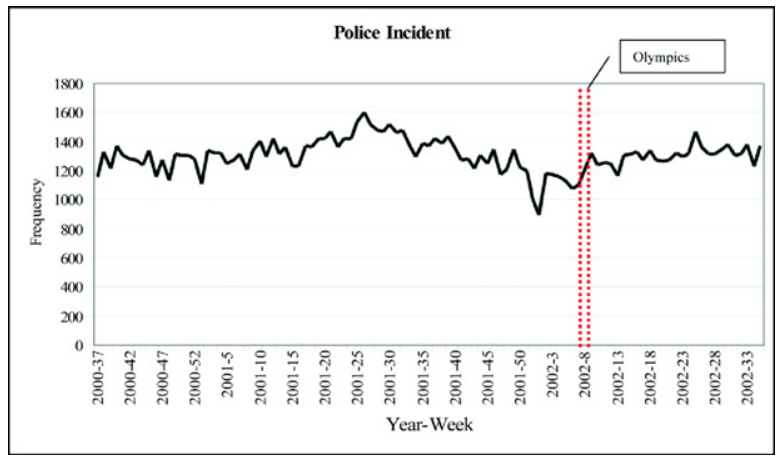

Fig. 3. Arrest trends

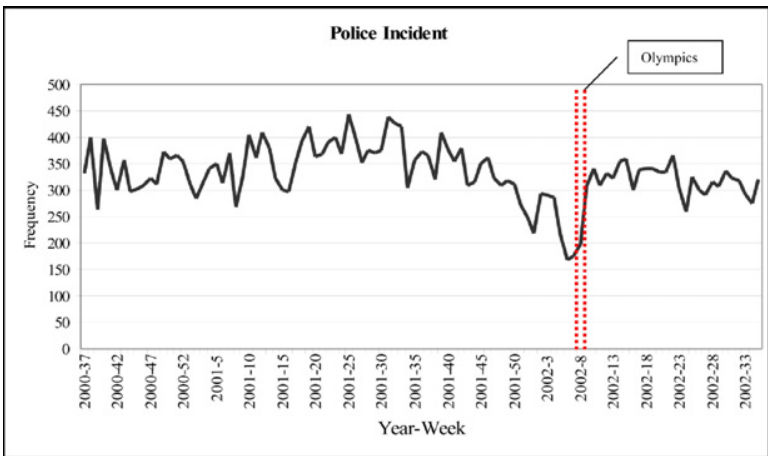

\section{Notes}

1. The balance between Utah and federal officers was important as it represented the largest federal presence in numbers and proportion in safety and security of all Olympics hosted in the United States.

2. The time series was extended through the summer of 2002. There was a precipitous increase in the number of calls in the beginning of June 2002. This seemed to correspond with the disappearance of Elizabeth Smart, the fourteen-year-old Salt Lake City resident who was kidnapped from her family home and subsequently reunited with her family in March of 2003. This event might be a historical artifact that represented an increase in the postgames mean weekly calls for service.

3. For additional information about diagnosing and estimating the $p, d, q$ parameters for ARIMA models see McDowall et al. (1980) and Box, Jenkins, and Reinsel (1994).

4. The initial spike indicated an autoregressive process where observation points were influenced by their preceding values, and the sustained nature of the spikes indicated a second order relationship or $p$ value of 2.0 (see McDowall et al., 1980). The tentative ARIMA $(2,0,0)$ model was run on SPSS $12.0(2000)$. To test if the data fit the model, the generated error term for each observation was modeled using the same autocorrelation diagnostic procedure identified above. If the data fit the model, the lagged error terms should fall within the lower and upper confidence intervals of the distribution and each lag period should have a nonsignificant probability or Q-statistic for each lag. The autocorrelograms indicated each error terms fall within the expected bounds, and the nonsignificant probabilities indicated the series was reduced to white noise or random error. The same procedure was run on the complete series of data that included the observation points before, during, and after the games. The same model fit the complete data series (autocorrelograms not shown). Thus, the data series for the calls for service data fit the ARIMA $(2,0,0)$ model.

5. The ACF and PCF autocorrelograms of the raw frequencies for weekly aggregations of police incidents are available for review from the authors. They were not included here for reasons of parsimony.

\section{References}

Alpert, G., \& Flynn, D. (2000). Community policing and major special events: A case study of Super Bowl XXXIII. In C. Brito, E. Corina, \& E. Gratto (Eds.), Problem oriented policing (pp. 169-185). Washington, DC: Police Executive Research Forum.

Blackout History Project. (1965). Great Northeast blackout. Retrieved from http://blackout.gmu.edy/events/t1965.html

Blackout History Project. (1977). New York blackout. Retrieved from http://blackout.gmu.edy/events/t1977.html

Box, G. E. P., \& Jenkins, G. M. (1976). Time series analysis. San Francisco: Holden-Day.

Box, G. E. P., Jenkins, G. M., \& Reinsel, G. C. (1994). Time series analysis (3rd ed.). Englewood Cliffs, NJ: Prentice Hall.

Box, G. E. P., \& Tiao, G. C. (1975). Intervention analysis with applications to economic and environmental problems. Journal of the American Statistical Association, 70, 70-79.

Brantingham, P. L., \& Brantingham, P. J. (1993). Environment, routine, and situation: Toward a pattern theory of crime. In R. V. Clarke, \& M. Felson (Eds.), Routine activity and rational choice (pp. 259-294). New Brunswick, NJ: Transaction. 
Brantingham, P. L., \& Brantingham, P. J. (1995). Criminality of place: Crime generators and crime attractors. European Journal on Criminal Policy and Research, 3, 5-26.

CNN. (2003). Power returns to most areas hit by blackout. Retrieved August 15, 2003, from http://www.cnn.com/2003/US/08/15/ power.outage/

Cohen, L. E., \& Felson, M. (1979, August). Social change and crime rate trends: A routine activity approach. American Sociological Review, 44, 588-608.

Decker, S. H., Greene, J. R., Webb, V., Rojek, J., McDevitt, J., Bynum, T., et al. (2005). Safety and security at special events: The case of the Salt Lake City Olympic Games. Security Journal, 18, 65-74.

Genevie, L., Kaplan, S. R., Peck, H., Struening, E. L., Kallos, J. E., Muhlin, G. L., et al. (1987). Predictors of looting in selected neighborhoods of New York City during the blackout of 1977. Sociology and Social Research, 71, 228-2131.

Governor's Office, State of Utah. (2002). Olympic security review conference. Salt Lake City, UT: Author.

Hansen, R. J. (2003). Reports of crime limited to looting: Arrests few. Retrieved from the Detroit News Web site: http://www.detnews. com/2003/metor/0308/17/a07-245903.htm
Lemieux, F. (1998). Altruism catastrophe and criminality: The case of the ice storm in Quebec in January 1998. Dissertations Abstracts International, 63(8), 3013-A.

McDowall, D., McCleary, R., Meidinger, E. E., \& Hay, R. A., Jr. (1980). Applied time series analysis for the social sciences. Beverly Hills, CA: Sage.

Schwendiman, D. (2001). The bar, the courts, criminal justice and the Olympics: Handling the impact of the Olympic Games on the courts, law practice and criminal justice in Utah. Utah Bar Journal, 8, 8-14.

Siegel, J. M., Bourque, L. B., \& Shoaf, K. I. (1999). Victimization after a natural disaster: Social disorganization or community cohesion? International Journal of Mass Emergencies and Disasters, 17, 265-294.

Wasn't so calm after all: Shootings, break-ins rose in the city during the blackout. (2003). Retrieved from the New York Daily News Web site: http://www.dailynews.com/news/story/1100818p$100132 \mathrm{c} . \mathrm{htm}$ 